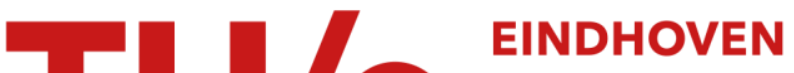

\section{Fault-tolerant epoxy-silane coating for corrosion protection of magnesium alloy AZ31}

\section{Citation for published version (APA):}

Lamaka, S. V., Xue, H. B., Meis, N. N. A. H., Esteves, A. C. C., \& Ferreira, M. G. S. (2015). Fault-tolerant epoxysilane coating for corrosion protection of magnesium alloy AZ31. Progress in Organic Coatings, 80, 98-105. https://doi.org/10.1016/j.porgcoat.2014.11.024

DOI:

10.1016/j.porgcoat.2014.11.024

Document status and date:

Published: 01/01/2015

\section{Document Version:}

Publisher's PDF, also known as Version of Record (includes final page, issue and volume numbers)

\section{Please check the document version of this publication:}

- A submitted manuscript is the version of the article upon submission and before peer-review. There can be important differences between the submitted version and the official published version of record. People interested in the research are advised to contact the author for the final version of the publication, or visit the $\mathrm{DOI}$ to the publisher's website.

- The final author version and the galley proof are versions of the publication after peer review.

- The final published version features the final layout of the paper including the volume, issue and page numbers.

Link to publication

\section{General rights}

Copyright and moral rights for the publications made accessible in the public portal are retained by the authors and/or other copyright owners and it is a condition of accessing publications that users recognise and abide by the legal requirements associated with these rights.

- Users may download and print one copy of any publication from the public portal for the purpose of private study or research.

- You may not further distribute the material or use it for any profit-making activity or commercial gain

- You may freely distribute the URL identifying the publication in the public portal.

If the publication is distributed under the terms of Article 25fa of the Dutch Copyright Act, indicated by the "Taverne" license above, please follow below link for the End User Agreement:

www.tue.nl/taverne

Take down policy

If you believe that this document breaches copyright please contact us at:

openaccess@tue.nl

providing details and we will investigate your claim. 


\title{
Fault-tolerant hybrid epoxy-silane coating for corrosion protection of magnesium alloy AZ31
}

\author{
S.V. Lamaka ${ }^{a, *}$, H.B. Xue ${ }^{a}$, N.N.A.H. Meis ${ }^{b}$, A.C.C. Esteves ${ }^{b}$, M.G.S. Ferreira ${ }^{a, c}$ \\ a ICEMS, Instituto Superior Técnico, Universidade de Lisboa, Av. Rovisco Pais 1, 1049-001 Lisbon, Portugal \\ ${ }^{\mathrm{b}}$ Materials and Interface Chemistry Group, Department of Chemical Engineering E Chemistry, Eindhoven University of Technology, 5612AZ Eindhoven, \\ The Netherlands \\ ${ }^{c}$ CICECO/DECV University of Aveiro, 3810-193 Aveiro, Portugal
}

\section{A R T I C L E I N F O}

\section{Article history:}

Received 8 October 2014

Received in revised form

27 November 2014

Accepted 28 November 2014

Available online 18 December 2014

\section{Keywords:}

Magnesium alloy

AZ31

Epoxy-silane coating

Corrosion

EIS

Inhibitor

\begin{abstract}
A B S T R A C T
In this work, a hybrid epoxy-silane coating was developed for corrosion protection of magnesium alloy AZ31. The average thickness of the film produced by dip-coating procedure was $14 \mu \mathrm{m}$. The adhesion strength of the epoxy-silane coating to the Mg substrate was evaluated by pull-off tests and was found to be higher than $16 \mathrm{MPa}$ both in dry and wet conditions. The hybrid epoxy-silane coating showed high corrosion resistance both when intact and when punched through by a needle. The low frequency impedance of intact coating was higher than $1 \mathrm{G} \Omega \mathrm{cm}^{2}$ after one month of immersion in $3.5 \% \mathrm{NaCl}$ solution. Both, artificially induced defects and corrosion sites that appeared on the metal surface did not propagate. Their passivation behavior, that we call fault-tolerance, was observed by EIS, SVET-SIET and SEM-EDS. It was ascribed to the good adhesion, high coating integrity and corrosion inhibiting effect provided by diethylenetriamine used as epoxy hardener.
\end{abstract}

(c) 2014 Elsevier B.V. All rights reserved.

\section{Introduction}

Surface treatment is one of the most effective approaches to prevent corrosion of highly electrochemically active magnesium and its alloys. Application of organic or hybrid coatings allows for achieving durable surface protection without detrimental effect on the mechanical properties of this light construction metal. To perform its duty effectively, protective coating must possess intrinsic durability, good adhesion to the substrate, adequate flexibility and toughness to withstand impacts and cracking as well as maintain its appearance when subjected to stress, swell, mechanical abuse or weathering [1].

Hybrid organic-inorganic coatings have been extensively studied because incorporation of inorganic components into organic networks results in formation of highly protective layers against corrosion. They also exhibit a wide range of improved multifunctional properties, including tensile strength, toughness, impact strength and thermal stability [2]. Inorganic component of the hybrid coating ensures good adhesion because of the formation

\footnotetext{
* Corresponding author. Tel.: +351 963419013.

E-mail address: sviatlana.lamaka@ist.utl.pt (S.V. Lamaka).
}

of chemical bonds between metal and hybrid film, while organic constituent increases the cross-link density and flexibility, reduces defects and improves compatibility with polymer coatings. Hybrid coatings gradually displace conventional conversion treatment of metal alloys since they combine the desirable properties of organic polymers with those of inorganic solids, providing effective barrier and conferring good adhesion [3,4].

Organo-functional silanes have been studied as pre-treatments for magnesium alloys $[1,3,5]$. These treatments provide surface functionality, improving the compatibility of the metallic substrate with the coating, which offer a linkage between metal surface and polymer primer through covalent bonds of a hydrolysable silicate group. E.g. phosphonate groups have more affinity on the magnesium surface than silane head-groups, thus forming a sol-gel coating with phosphonate binding to magnesium surface [6]. Tris(trimethylsilyl) phosphate was found to improve significantly corrosion protection of the Mg alloy when copolymerization of epoxy-siloxane and titanium or zirconium alkoxides [7]. The chemical structure of a cross-linking agent may affect coating properties. For example, amino-silanes are unique adhesion promoters, which can be involved not only in the conventional chemistry of bonding epoxy groups, but can also undergo sol-gel hydrolysis and condensation reactions and acting simultaneously as coupling agents to the substrate [8]. 
Epoxy resins have found widespread usage in the coating industry due to excellent adhesion to metals and high resistance to chemicals and corrosion. The high chemical stability of cured epoxy has been ascribed to the presence of stable carbon-carbon and ether bonds in the backbone of the epoxy molecule. However, these resins have fairly poor mechanical properties, inferior thermal and weathering stabilities, which limit their high-performance applications in coating systems $[9,10]$. Technical literatures present hybrid epoxy-siloxane coatings as excellent protective coatings because of formation of dense - $\mathrm{Si}-\mathrm{O}-\mathrm{Si}-$ network chemically bonded to lateral epoxy organic chains $[11,12,13]$. These coatings have greater durability and better resistance to atmospheric degradation, heat, chemical attack and UV radiation than coatings with other organic polymers. Such hybrid epoxy-silane coatings are applied for steel protection for years $[12,13,14]$ but were not used for protecting magnesium alloys until recently [15-17].

In our previous publication [15], the protective performance of several epoxy-silane coatings which differed by the type of silane (aminopropyltriethoxysilane (APTES), aminopropyltrimethoxysilane (APTMS), 3-(glycidoxypropyl)trimethoxysilane (GPTMS) and tris(trimethylsilyl)phosphate (TMSPh)) was compared when immersed in dilute $0.05 \mathrm{M} \mathrm{NaCl}$ solution. The results demonstrated that the APTMS and APTES based coatings provided durable protection to AZ31 alloy. APTES-based epoxy-silane coating used for sealing porous anodic film produced by DC plasma electrolytic oxidation on ZE41 magnesium alloy was also shown to improve significantly the protective properties of the duplex coating [18]. In this work we focused on adhesion of APTES-based epoxy-silane coating to AZ31 substrate, its protective behavior in concentrated $3.5 \%(0.61 \mathrm{M}) \mathrm{NaCl}$ solution and on fault-tolerance effect of the coating applied to AZ31: either artificial or naturally occurring defects were found to not propagate during short- or long-term exposure to corrosive electrolyte.

\section{Experimental}

\subsection{Materials}

The AZ31 magnesium alloy with the following chemical composition was used: 3.0 (wt.\%) Al, $0.83 \mathrm{Zn}, 0.31 \mathrm{Mn}, 0.01 \mathrm{Si}, 0.003$ $\mathrm{Fe}, 0.001 \mathrm{Cu}, 0.001 \mathrm{Ni}$ and $\mathrm{Mg}$ balance. The alloy was cut into the coupons with the dimension of $25 \mathrm{~mm} \times 40 \mathrm{~mm} \times 2 \mathrm{~mm}$. The coupons were mechanically ground with silicon carbide papers $\# 320,500$ and 1200, then activated in 12\% hydrofluoric acid for 15 min, dipped in abundant water for a few seconds, and then dried well with pressurized air.

\subsection{Coating preparation procedures}

The coating components were purchased from Sigma-Aldrich and used as received, without extra purification. The coating solution consisted of three main ingredients: aminopropyltriethoxysilane (APTES, Ref. 741442), poly(bisphenol A-coepichlorohydrin)glycidyl end-capped (Ref. 387703) and diethylenetriamine (DETA, Ref. 93856). The silane and epoxy components were first prepared separately, by dissolving them in ethanol and acetone, and stirring for $1 \mathrm{~h}$. Then two solutions were mixed and the amine was added. The concentration of the main components in that final solution was $3 \mathrm{wt} . \%$ silane, $35 \mathrm{wt}$.\% epoxy and $4 \mathrm{wt} . \%$ amine. The mixed components were stirred for $6 \mathrm{~h}$ at room temperature. The pre-treated AZ31 substrates were dipped into the prepared solution and removed at a controlled speed of $36 \mathrm{~cm} / \mathrm{min}$, using a RDC 15 laboratory dip coater from Bungard Elektronik. Finally, the coated samples were cured in the oven at $150^{\circ} \mathrm{C}$ for $1.5 \mathrm{~h}$.

\subsection{Experimental techniques}

Electrochemical impedance spectroscopy (EIS) was employed to evaluate the corrosion protection performance of the developed coating on AZ31 during immersion in 3.5 wt.\% $(0.61 \mathrm{M}) \mathrm{pH}$ neutral $\mathrm{NaCl}$ solution for one month. EIS measurements were carried out using an AUTOLAB Potentiostat/Galvanostat (PGSTAT302N) coupled with a frequency response analyzer at open circuit potential. A $10 \mathrm{mV}$ of sinusoidal perturbation was applied in the frequency range of $100 \mathrm{kHz}$ to $10 \mathrm{mHz}$. A conventional three-electrode cell was used, consisting of a saturated calomel reference electrode, a platinum coiled wire as counter electrode and the coated AZ31 as working electrode. The active area of tested working electrode was $3.2 \pm 0.2 \mathrm{~cm}^{2}$. The measurements were performed at room temperature in a Faraday cage in order to avoid any electromagnetic interference. The total volume of electrolyte in the cell was $10 \mathrm{~mL}$, it was quiescent and equilibrated with air.

DC potentiodynamic polarization measurements were performed separately in anodic and cathodic ranges vs. OCP at a scan rate of $0.5 \mathrm{mV} / \mathrm{s}$. The coupon of AZ31 was embedded in epoxy resin and polished after the resin hardened. The OCP against SCE was monitored for $10 \mathrm{~min}$ before the polarization measurements. Abraded coupons of AZ31 alloy used for polarization measurements were not coated with epoxy-silane coating. At least two repetitions for each set of parameters (polarization range, electrolyte concentration) were performed. The measurements were performed either in $0.05 \mathrm{M} \mathrm{NaCl} \mathrm{pH}$ neutral electrolyte or in either $1 \times 10^{-2} \mathrm{M}$ DETA or $1 \times 10^{-3} \mathrm{M}$ DETA solution prepared in $0.05 \mathrm{M} \mathrm{NaCl}$.

Scanning vibrating electrode technique (SVET) and scanning ion-selective electrode technique (SIET) [19] were used to measure the local current density and local $\mathrm{pH}$ distribution around a pin-hole defect $(d=100 \mu \mathrm{m})$ intentionally induced by a needle in the coating and reaching to the Mg substrate. The SVET is designed to respond to the potential gradients in the ionic solution associated with the flow of current. A commercial SVET-SIET equipment, manufactured by Applicable Electronics ${ }^{\mathrm{TM}}$ and controlled by ASET software (Science Wares ${ }^{\mathrm{TM}}$ ) was used. SVET and SIET measurements were performed quasi-simultaneously as described in [20]. Briefly, an insulated Pt-Ir microelectrode (Microprobes Inc.) used as vibrating electrode for SVET measurements was platinized to improve the signal to noise ratio. The diameter of the resulted ball of platinum black was $15 \pm 3 \mu \mathrm{m}$. The probe was placed $100 \pm 5 \mu \mathrm{m}$ above the coating surface, vibrating in the horizontal $(X)$ and vertical $(Z)$ planes relative to the cell surface with amplitudes of $17 \mu \mathrm{m}$. The vibration frequencies of the probe were $128 \mathrm{~Hz}(X)$ and $325 \mathrm{~Hz}(Z)$. Local $\mathrm{pH}$ around the defect was measured using pH-selective glass-capillary microelectrode, which was positioned $50 \pm 5 \mu \mathrm{m}$ above the coating surface. Silanized glass micropipettes were back-filled with an inner reference solution and tip-filled with 4-nonadecylpyridine-based $\mathrm{H}^{+}$selective liquid membrane [21]. The diameter of the tip opening of glass-capillary microelectrodes was $1.8 \pm 0.3 \mu \mathrm{m}$. The column length of the membrane was ca. $60 \mu \mathrm{m}$. An $\mathrm{Ag} / \mathrm{AgCl}$ wire was inserted into the electrolyte to provide the inner reference electrode. The $\mathrm{pH}$-selective microelectrodes were calibrated using commercially available $\mathrm{pH}$ buffers in a pH range from 2 to 10 and demonstrated linear Nernstian response of $-55.2 \pm 1.0 \mathrm{mV} / \mathrm{pH}$. The vibrating probe of SVET and the glass-capillary microelectrode of SIET were positioned at a distance of $50 \mu \mathrm{m}$. A time lag between acquiring each current density and $\mathrm{pH}$ data-point was $1.5 \mathrm{~s}$. Thus, one SVET-SIET scan yielded two independent maps showing ionic current density and $\mathrm{pH}$ distribution. Experiments were performed during continuous immersion in $0.05 \mathrm{M} \mathrm{NaCl}$, the cell was placed in a Faraday cage at room temperature $\left(21 \pm 3^{\circ} \mathrm{C}\right)$.

Pull-off adhesion tests were performed to classify the adhesion strength of the coatings to the different substrates. The pull-off 
test was performed using an Easy TEST (EZ20) tensile equipment, employing a velocity of $1 \mathrm{~mm} \mathrm{~min}^{-1}$. Two sets of coated samples were prepared to test the adhesion: one was prepared in dry conditions and the other was immersed in distilled water for one week. Four parallel samples in dry conditions and two in wet conditions were measured and the average value was taken. The edges of the samples immersed in distilled water were sealed by waterproof tape before immersion. After immersion, the samples were dried with compressed $\mathrm{N}_{2}$. The coating surfaces of all samples were ground by silicon carbide paper (\#1200, $3 \mathrm{M})$ to enhance the mechanical anchoring of the glue (3 M Scotch-weld DP460) which attached the stud perpendicularly to the coating surface. After application, the glue was cured at $20^{\circ} \mathrm{C}$ for two days before the pull-off test was done. An electrical drill was used to remove the coating around the stud. The force needed to detach the coating at an angle of $90^{\circ}$ from the substrate was monitored as a function of the stud displacement. Only the loading of adhesive failure was recorded. Further details about the pull-off test can be found in literature $[22,23]$.

The coating thickness was measured using a digital Elcometer 355 by the appropriate gauge and calibration standards. Measurements were performed at a minimum of five points on the sample surface in order to get a reliable value. The microstructure and general chemical composition of the coating before and after immersion were characterized by JEOL 7001F FEG scanning electron microscope (SEM), coupled with energy dispersive X-ray spectroscopy (EDS) at accelerating voltage of $15 \mathrm{keV}$. OLYMPUS ILLC2 optical microscope coupled with optical camera was also used for examining the surface of coated AZ31 magnesium alloy.

\section{Results and discussion}

\subsection{Barrier properties of the coating by EIS measurements}

The coated AZ31 substrates were observed visually and by SEM prior immersion tests and electrochemical measurements. The coating was homogeneous and compact, without apparent defects on the surface. The thickness measured with an Elcometer ranged from 12 to $15 \mu \mathrm{m}$, with the average being $14 \mu \mathrm{m}$. This result was coherent with the one deducted from SEM cross-sectional view, Fig. 1, where the measured thickness of coating was about $13.7 \mu \mathrm{m}$. Note that the coating was well adherent to the AZ31 magnesium substrate.

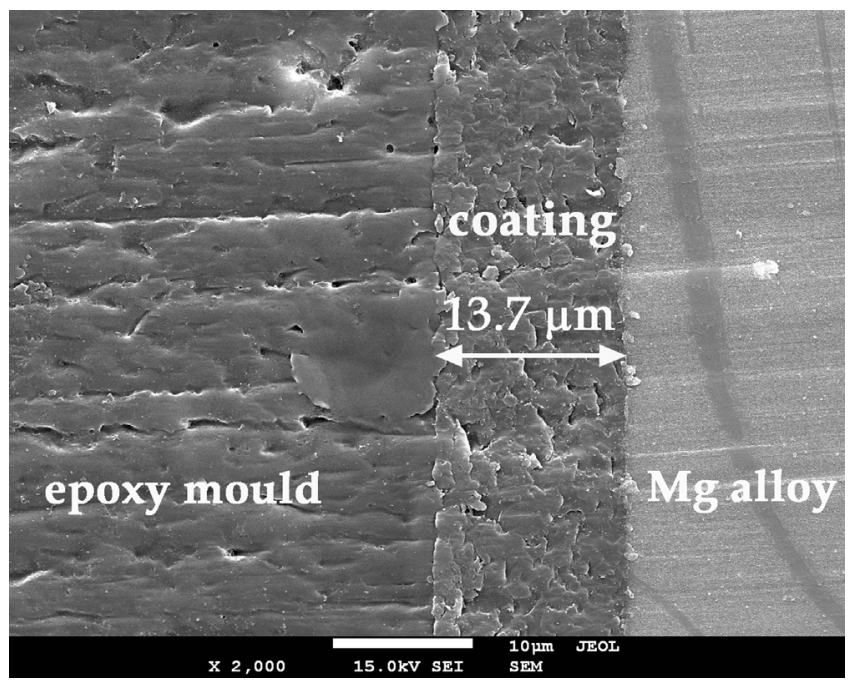

Fig. 1. Cross-sectional SEM micrograph of as prepared epoxy-silane coating deposited on magnesium alloy AZ31.

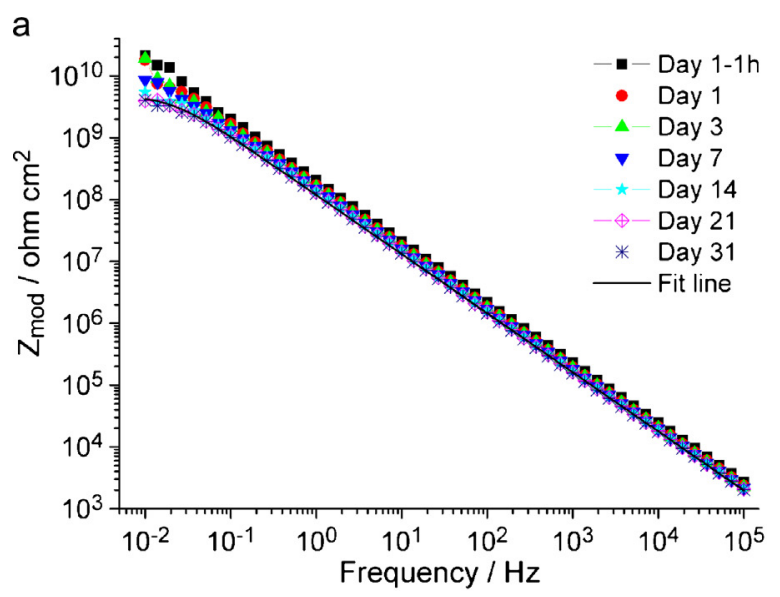

b

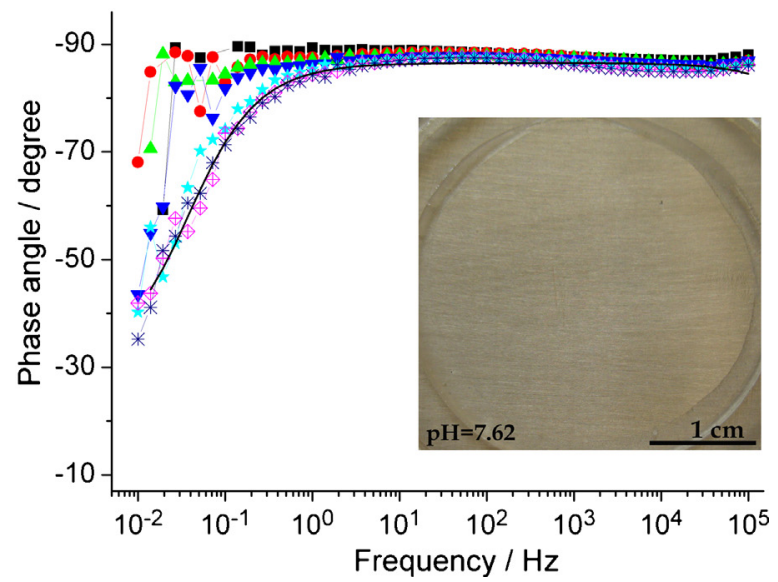

Fig. 2. Evolution of EIS Bode plots of the epoxy-silane coating deposited on AZ31 during immersion in $3.5 \% \mathrm{NaCl}$ solution for 31 days. The inset shows the visual appearance of the sample at the end of immersion test and the bulk $\mathrm{pH}$.

The protective performance of the coating was studied by EIS during immersion in $3.5 \mathrm{wt} . \%(0.61 \mathrm{M}) \mathrm{NaCl}$ solution. Fig. 2 presents the Bode plots on the coated AZ31 Mg alloy. Purely capacitive response with the phase angle close to $-90^{\circ}$ in the frequency range from $100 \mathrm{kHz}$ to $0.1 \mathrm{~Hz}$ was observed during the first week of immersion. This response was associated with the hybrid epoxy-silane coating. After two weeks of immersion, the impedance spectra revealed a small time constant in the medium frequency range related to the responses of interfacial magnesium oxides/hydroxide. The Bode plots, Fig. 2, show that the capacitance increased and low frequency impedance decreased only slightly during one month of immersion with the final value of the low frequency impedance being ca. $4 \times 10^{9} \Omega \mathrm{cm}^{2}$, indicating that the coating was intact and provided good barrier protection. Obtained EIS spectra are fully in line with the optical appearance of the sample after 1 month of immersion presented in the insert in Fig. 2. Neither signs of corrosion attack nor coating degradation are visible.

More detailed analysis was achieved by fitting the EIS spectra presented in Fig. 2. The proposed equivalent circuits (EC) are shown in Fig. 3. The fit lines presented in Fig. 2 were obtained by fitting the spectrum recorded after 14 days of immersion. Due to the changes in the coated alloy during the immersion process, two different equivalent circuits were used to fit the measured EIS data. At the beginning of immersion, impedance spectra could be adequately fitted by the equivalent circuit that included only one time constant representing epoxy-silane coating, as shown in the insert in Fig. 3a. The equivalent circuit with two time constants, which was used 
a)

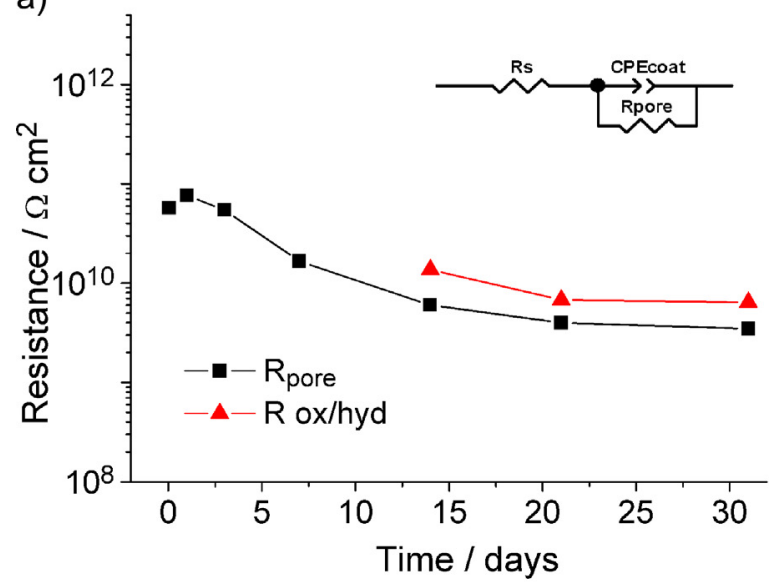

b)

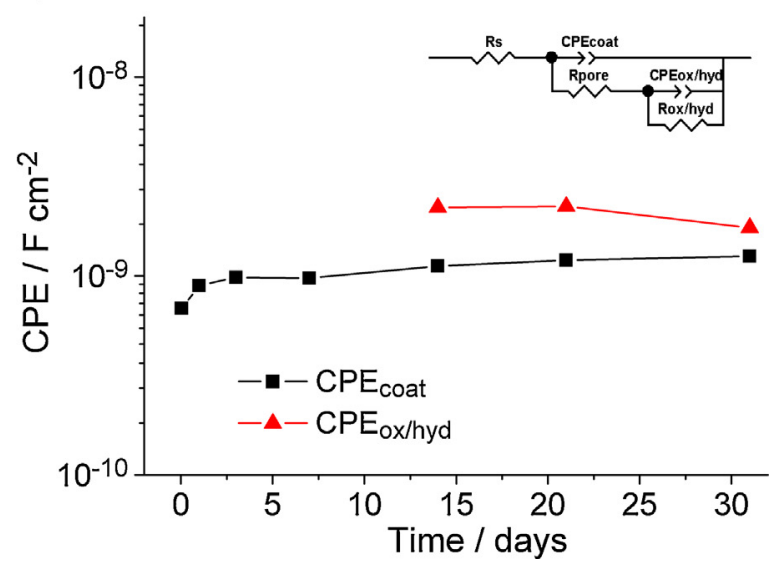

Fig. 3. Evolution of resistance (a) and CPE (b) of the hybrid epoxy-silane coated samples during immersion in $3.5 \% \mathrm{NaCl}$ solution for 1 month. The insets show the equivalent electrical circuits for fitting the EIS data: (a) for $1 \mathrm{~h}$ to 7 days and (b) for 14-31 days.

to fit the EIS spectra between 14 and 31 days is shown in Fig. $3 \mathrm{~b}$. In both EC, the capacitance was replaced by a constant phase element (CPE) which accounted for non-homogeneity of the systems and therefore deviations from the ideal capacitive behavior. The CPE could be defined by $\mathrm{CPE}=(j \omega)^{-n} / Y_{0}$, with the parameters: frequency $(\omega)$, pseudo-capacitance $\left(Y_{0}\right)$ and $n$ associated to the system homogeneity [24]. $\mathrm{CPE}_{\text {coat }}$ and $R_{\text {pore }}$ are related to the capacitive response and pore resistance of the epoxy-silane coating. The coating capacitance $\mathrm{CPE}_{\text {coat }}$ was related to the diffusion behavior of electrolyte into the coating; and the pore resistance $R_{\text {pore }}$, which reflected the anti-penetrating ability of the coating to electrolyte through the coating pores, was an important parameter to evaluate corrosion resistance of the coating. The time constant at medium frequencies $\left(\mathrm{CPE}_{\mathrm{ox} / \mathrm{hyd}} / R_{\mathrm{Ox} / \mathrm{hyd}}\right)$ was assigned to the interfacial $\mathrm{Mg}$ oxide/hydroxides layer underneath the coating. The evolution of the resistance and capacitance values as a function of immersion time are depicted in Fig. 3.

The fitting results demonstrate that there was only slight increase of $R_{\text {pore }}$ during the first days of immersion due to the water uptake by the coating, which resulted in swelling and increasing the resistance of the coating. After the first three days, the coating resistance slightly decreases due to the continuous penetration of the electrolyte into the pores of the coating. The second time constant that appeared after two weeks of represents the metastable activity when the electrolyte reached the oxides/hydroxides layer. In general, rather stable behavior of the coating resistance was observed which slightly decreased but
Table 1

Adhesion strength of hybrid epoxy-silane coating applied to magnesium alloy AZ31. Measured by pull-off tests for as coated samples (dry) and after one week of immersion in distilled water (wet)

\begin{tabular}{lcc}
\hline Substrate AZ31 & Dry & Wet (1 week) \\
\hline Average adhesion strength (MPa) & 17.0 & 16.2 \\
Standard deviation (MPa) & 6.0 & 2.2 \\
Detached area (\%) & 0 & 5 \\
Number of samples tested & 4 & 2 \\
\hline
\end{tabular}

remained at $4 \mathrm{G} \Omega \mathrm{cm}^{2}$, suggesting that the epoxy-silane layer continued to provide corrosion protection to the substrate through its barrier properties. Coating capacitance presented in Fig. 3 changed very slightly along with $R_{\text {pore }}$. The results showed that CPE values slightly increased during the initial period of immersion and reached stable values. The values of $R_{\mathrm{ox} / \mathrm{hyd}}$ could be quantified only after two weeks of immersion and slightly decreased during the immersion period to the final value of ca. $6 \mathrm{G} \Omega \mathrm{cm}^{2}$. Corresponding $\mathrm{CPE}_{\text {hyd }}$ values remained stable in time, demonstrating that the corrosion protection of oxides/hydroxides intermediate layer stayed high during immersion. The fitted data is also in line with the visual appearance of the sample shown in the insert in Fig. 2. However, the $\mathrm{pH}$ value of bulk $\mathrm{NaCl}$ solution measured after one month of immersion, $\mathrm{pH}=7.62$, is slightly higher that the $\mathrm{pH}$ of the initial $\mathrm{NaCl}$ solution (6.0). Thus, although good overall protective properties of the coating are confirmed, slight increase of $\mathrm{pH}$ value suggests that the minor changes occurred either in the coating or at the coating/metal interface. Even marginal release of DETA that did not react with the epoxy component at the stage of coating preparation could cause observed $\mathrm{pH}$ change. Measured $\mathrm{pH}$ of the electrolyte containing $0.05 \mathrm{M} \mathrm{NaCl}+1 \times 10^{-2} \mathrm{M}$ DETA was as high as 11.10 . The second cause for the observed $\mathrm{pH}$ could have been weak corrosion of magnesium alloy under the coating. We explore these effects in the following parts of this article.

\subsection{Corrosion and adhesion at coating-substrate interface}

To understand better the processes at the coating/metal interface, the coating was detached from sample that has been immersed in $3.5 \% \mathrm{NaCl}$ solution for one month. Note, that detaching the coating was not easy as it possessed high adhesion strength, as discussed below, see Table 1 . Only small area of the coating could be detached with the scalpel. The surface of the sample from which the coating has been detached presented a few single "dots" of regular shape of ca. $20-50 \mu \mathrm{m}$ in diameter, see Fig. 4a. The EDS analysis of the "dot-zone" shown in Fig. $4 \mathrm{~b}$ revealed considerable amount of $\mathrm{O}$ and the presence of $\mathrm{Cl}$ and $\mathrm{Al}$ among other elements, Fig. 4c. This means that $\mathrm{Cl}$-containing electrolyte soaked to the metal/coating interface, and started corrosion lead to formation of $\mathrm{MgO}$ and/or $\mathrm{Mg}(\mathrm{OH})_{2}$. However, corrosion onset stopped and the circle-like features did not grow further once they appeared at the coating-substrate interface. Such behavior is not typical to $\mathrm{Mg}$ alloy. Since magnesium alloys are highly electrochemically activity, corrosion usually propagates quickly once the corrosive electrolyte reaches $\mathrm{Mg}$ surface. Observed passivation phenomenon was attributed to the blockage of the pathways by the corrosion products found right in the middle of the precipitated circles, Fig. 4b. The mixture of $\mathrm{MgO}, \mathrm{Mg}(\mathrm{OH})_{2}, \mathrm{Al}_{2} \mathrm{O}_{3}$ and $\mathrm{Al}(\mathrm{OH})_{3}$ was likely to precipitate in the highly alkaline environment formed in confined space at the coating-substrate interface. Previously we reported that the local $\mathrm{pH}$ measured over active defects in coatings applied on Mg alloys can reach 8.5 [25], 9.8 [26] or even 11.4 [27]. Note that these $\mathrm{pH}$ values were measured over the active defect, while formed $\mathrm{OH}^{-}$freely diffused from the defect. The $\mathrm{pH}$ under the coating is expected to be even higher. Alkalinization occurred 


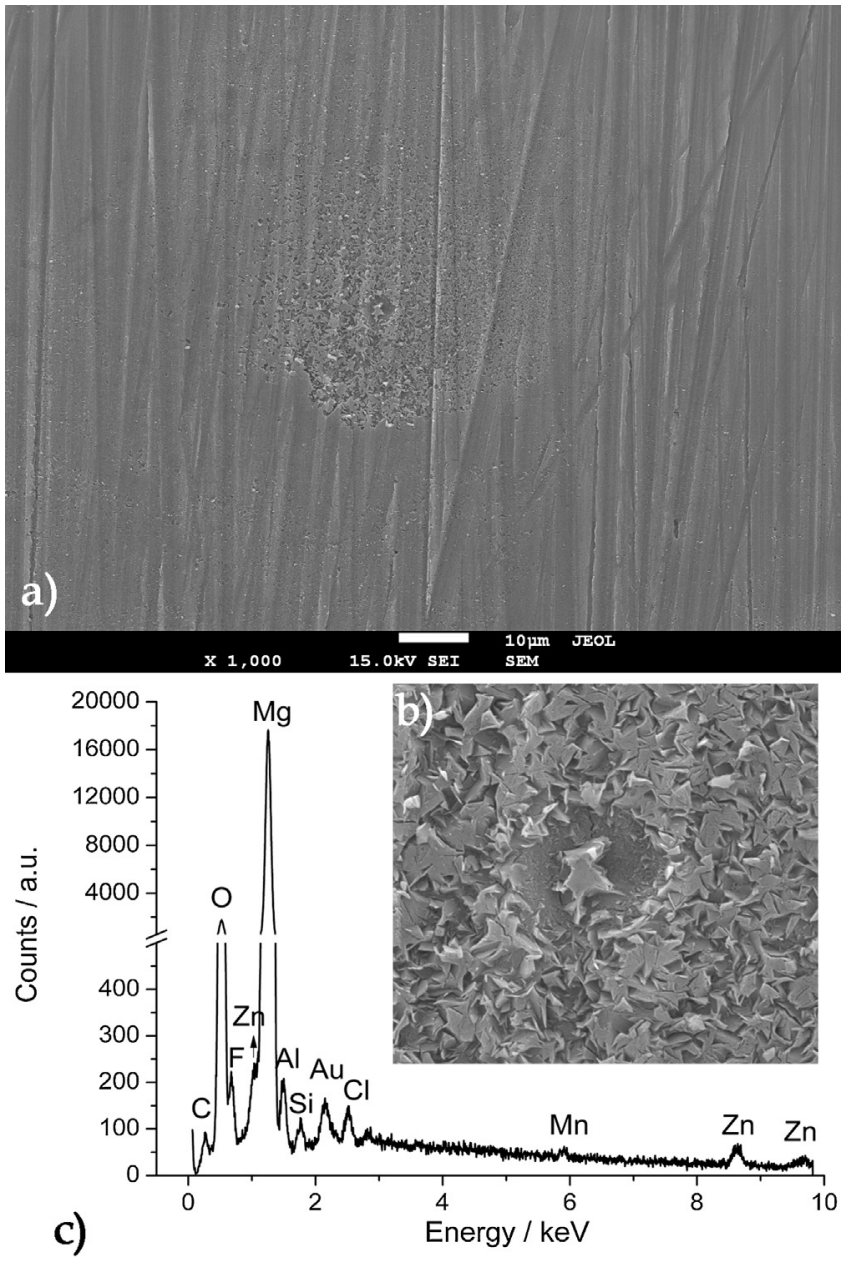

Fig. 4. (a) Morphology of corrosion products under the detached coating, (b) central area of the corrosion site at higher magnification and (c) corresponding EDS spectrum of area (b).

due to the cathodic water reduction, $2 \mathrm{H}_{2} \mathrm{O}+2 \mathrm{e}^{-} \rightarrow 2 \mathrm{OH}^{-}+\mathrm{H}_{2} \uparrow$, accompanied by hydrogen evolution. Because the typical corrosion potential of Mg alloys is around $-1.5 \mathrm{~V}$ (vs. saturated calomel electrode), the reduction of dissolved oxygen might also take place but the total amount of current is usually small compared to water reduction [28]. Said corrosion products blocked the pathways in the coating preventing access of the electrolyte from the bulk solution to the substrate resulting in the protection of the alloy surface from extensive corrosion attack and further coating degradation. Furthermore, possible inhibiting effect of the coating components on corrosion of AZ31 Mg alloy is discussed in Section 3.4 of this article.

Pull-off tests, Table 1, were performed to quantify the adhesion strength of the coating to the substrate in dry, as prepared conditions, and in wet conditions after one week of immersion in distilled water. The average adhesion strength under dry and wet conditions did not differ much. The adhesion strength of as prepared coating was $17.0 \pm 6.0 \mathrm{MPa}$, while the adhesion of the coating after one week exposure to distilled water was $16.2 \pm 2.2 \mathrm{MPa}$. This suggests that the highly cross-linked interfacial layer rather than the outermost epoxy-silane film is a major contributor in the corrosion protection. The interfacial layer anchored tightly to the substrate due to a high density of $\mathrm{Mg}-\mathrm{O}-\mathrm{Si}$ bonds formed at the interface, results in a high initial, "dry", adhesion of the coating [29]. High adhesion strength is also in agreement with the good corrosion protective properties as was measured by EIS.

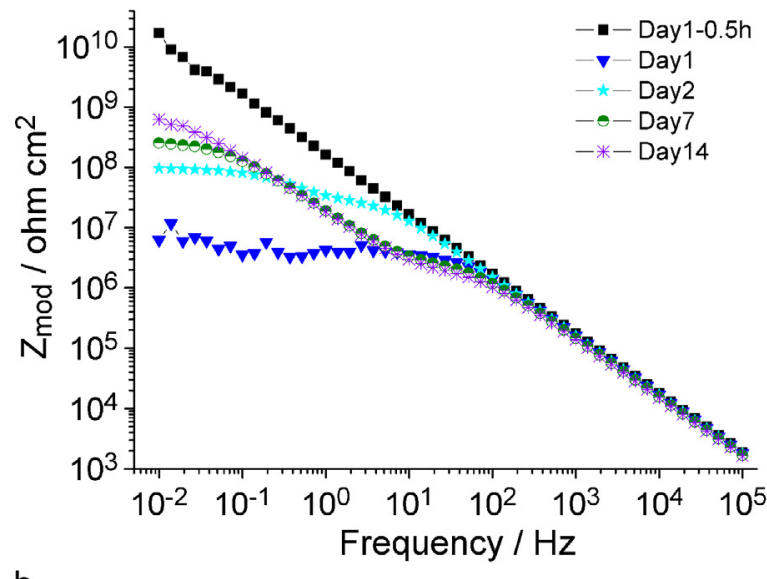

b

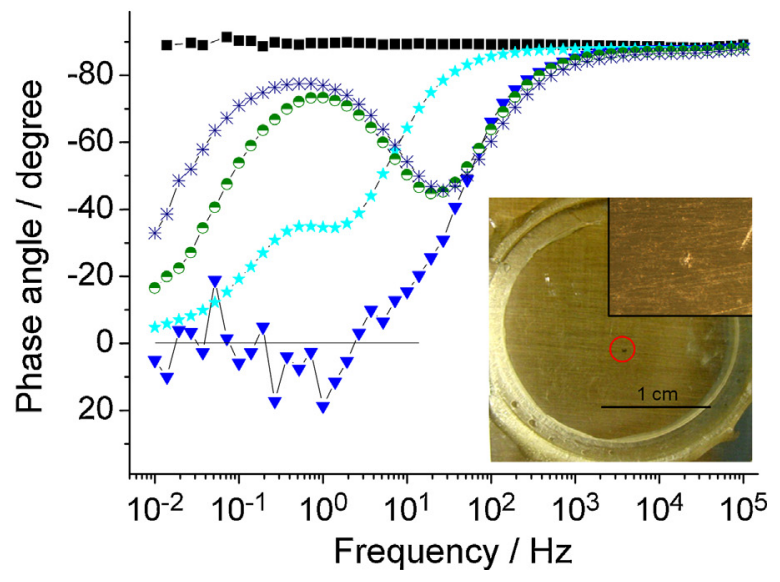

Fig. 5. Evolution of impedance spectra of the coated sample with the artificial defect during immersion in $3.5 \% \mathrm{NaCl}$ solution for 14 days. The inset presents the optical images of the defect on the coated alloy at lower and higher magnifications. Both optical images were taken after the immersion tests.

\subsection{Protective performance of the coating with the artificial defect}

To understand better possible corrosion mechanisms and the barrier properties of the coating, the behavior of intentionally damaged coating was studied by EIS and SVET-SIET. One artificial defect of ca. $100 \mu \mathrm{m}$ in diameter was created in each of two coated samples used for parallel impedance and local electrochemical measurements. The insert in Fig. 5 shows the "pin-hole" defect in the sample used for EIS measurements: the general view of the coating with the defect and magnified view of the same defect after 14 days of exposure to $3.5 \% \mathrm{NaCl}$ solution. Fig. 5 presents the evolution of EIS spectra as a function of immersion time. The first spectrum (Day 1 $0.5 \mathrm{~h}$ ), was recorded before the pin-hole defect was made in order to verify the protective properties of the coating. This spectrum is similar to the one for the parallel sample presented in Fig. 2, Day $1-1 \mathrm{~h}$. Right after the first impedance measurement, the defect reaching to the metallic substrate was made in the coating. The first impedance measurement for the sample with the defect (Day 1) shows significant decrease of high frequency impedance. Then, the impedance modulus steadily increases as the immersion time elapses. By the end of immersion, after 2 weeks of exposure to $3.5 \% \mathrm{NaCl}$, the impedance modulus at low frequency reached almost $10^{9} \Omega \mathrm{cm}^{2}$, which was only one order of magnitude lower than that at the beginning of immersion. This increase of impedance modulus at low frequency is caused by the accumulation of corrosion products 

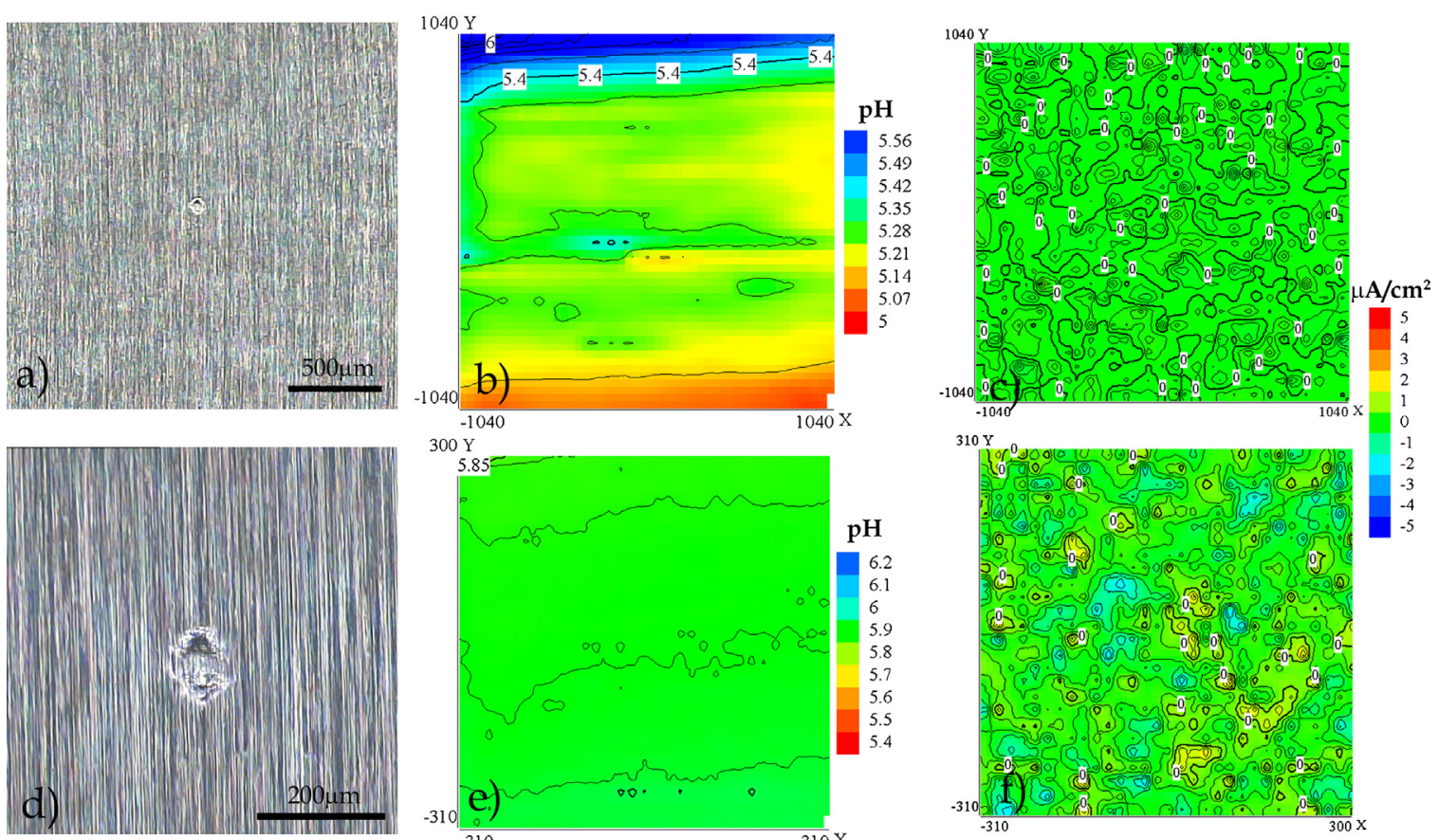

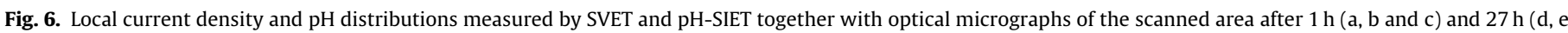
and f) of exposure to $0.05 \mathrm{M} \mathrm{NaCl}$ solution.

and blockage of the defect. Indeed, accumulation of whitish corrosion products is seen in the optical photograph in the insert in Fig. 5.

Fig. 6 shows the current density and $\mathrm{pH}$ distribution maps measured by SVET and SIET over the exposed coated surface together with optical micro-graph of the scanned area. At the beginning of immersion no corrosion activity was detected by SVET while very weak mixed corrosion activity was detected by $\mathrm{pH}$-microelectrode suggesting low rate anodic and cathodic process taking place in the defect. Note that certain discrepancy between SVET and SIET measurements is not surprising. We have previously observed that $\mathrm{pH}-\mathrm{microscopy}$ is more sensitive technique to detect the corrosion onset [30]. Any activity in the defect vanished after $27 \mathrm{~h}$ of continuous immersion. Increased noise in SVET map is related to the decreased probe capacitance. Increased pH (from 5.3 to 6.0 ) is the consequence of the corrosion reaction observed at the beginning of SVET-SIET measurements. Moreover, minor release of DETA from the coating, can also contribute to the change of $\mathrm{pH}$, see above. SVET/SIET measurements were in agreement with the EIS results. The results of both local and global electrochemical techniques showed that the developed epoxy-silane coating can withstand local damage providing effective corrosion protection.

\subsection{Fault-tolerance effect}

As described in previous parts of this manuscript, the faulttolerance effect was observed for several samples by different techniques. In case of intact coating this effect was identified at the alloy/coating interface by SEM-EDS when the apparent microdefect in the coating did not propagate but corrosion in the defect stopped. For the case of intentionally damaged coating, the fault-tolerance effect was observed by SVET-SIET as decrease of corrosion activity during short term immersion (27 h). Eventually, during the course of longer immersion (14 days), the effect of faulttolerance was identified by EIS measurements showing the increase of low frequency impedance in the case of intentionally damaged coating. In all these cases when the defect appeared and the coating failed locally, it kept its protective performance as a whole, able to tolerate local damage.

Although developed coating was not intentionally modified with any corrosion inhibitor, such behavior of the coating, demonstrating good barrier and active protection properties allows to assume that one of the coating components possessed corrosion inhibition ability. In order to verify this, potentiodynamic polarization measurements were performed. No effect of the aminopropyltriethoxysilane $\left(1 \times 10^{-2} \mathrm{M}\right.$ in $\left.0.05 \mathrm{M} \mathrm{NaCl}\right)$ on polarization curve was determined (data is not shown). Fig. 7 presents the polarization curves recorded either in pure $0.05 \mathrm{M} \mathrm{NaCl}$ electrolyte or in the same electrolyte were diethylenetriamine was added. In polarization measurements, lower corrosion density corresponds to lower corrosion rate, higher inhibiting effect and better corrosion resistance. Decrease of corrosion current density at anodic polarization demonstrates the inhibiting effect of DETA at both amine concentrations: $1 \times 10^{-3} \mathrm{M}$ and $1 \times 10^{-2} \mathrm{M}$. Recently, we have also found similar corrosion inhibition effect of DETA on magnesium alloy WE43 [31].

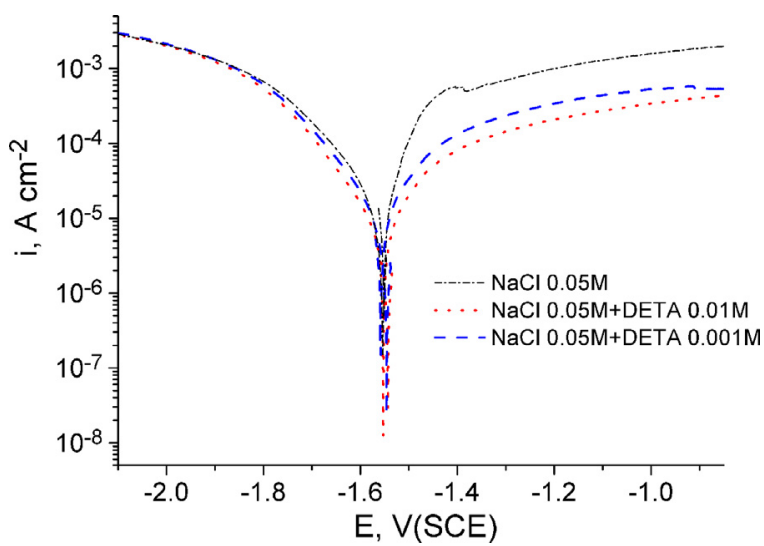

Fig. 7. Potentiodynamic polarization curves of untreated AZ31 alloy recorded either in pure $0.05 \mathrm{M} \mathrm{NaCl}$ or in $0.05 \mathrm{M} \mathrm{NaCl}$ with DETA. 
Thus, the fault-tolerance effect is a result of several factors: high chemical, mechanical and hydrolytic stability of the epoxybased hybrid coating. Good adhesion of the developed epoxy-silane coating to magnesium substrate that is achieved by adding silane component to the coating formulation. Combined with the intrinsic property of $\mathrm{Mg}$ to undergo anodic dissolution that is not accompanied by hydrolysis of $\mathrm{Mg}^{2+}$ ( $\mathrm{p} K_{\text {hyd }}^{1}=11.4$ [19]) that leads to fast alkalinization in the confined space under the coating, these factors favoured formation of stable corrosion products that blocked further access of corrosive environment and hence corrosion propagation. Active corrosion protection property of the coating owing to the corrosion inhibiting effect of DETA (used as epoxy hardener) is also an important contribution to the fault-tolerance effect characteristic for the developed hybrid epoxy-silane coating. As was shown above, when the coating failed locally, it kept its protective performance as a whole; it was able to tolerate local damage. We introduce the term "fault-tolerance effect" here as it seems to describe better (than "self-healing") the phenomena of durable and well adherent coating that tolerates local damage due to corrosion inhibiting effect provided by the coating as a whole (rather than encapsulated inhibitor distributed in the coating matrix) and/or accumulation of corrosion products in local defect while the "healing" of the coating matrix does not occur.

\section{Conclusions}

A hybrid epoxy-based coating with a silane component, APTES, was developed and applied to the magnesium alloy AZ31. The barrier properties of the coated samples were studied using EIS during immersion in $3.5 \mathrm{wt} . \% \mathrm{NaCl}$ solution for 1 month. The coating showed capacitive response with the value of low frequency impedance ca. $4 \mathrm{G} \Omega \mathrm{cm}^{2}$ indicating its high corrosion resistance and durability. It also possesses high adhesion strength based on the pull-off tests under both dry and wet conditions. Micro-defects naturally formed in the coating during the immersion, allowed for penetration of the corrosive electrolyte to the coating-substrate interface and initiated corrosion. However, the corrosion did not propagate at the coating-substrate interface due to the good adhesion, high coating integrity, corrosion inhibition provided by DETA and blockage of the electrolyte pathways by the corrosion products.

The protective performance of the coating with artificial defect was also evaluated by global and local electrochemical methods. SVET-SIET measurements showed weak activity in the defect that fully passivated after one day of immersion. The EIS results showed that the impedance values of the defected coating gradually increase due to the blocking effect of the corrosion products and corrosion inhibiting effect provided by DETA. The final low frequency impedance was $10^{9} \Omega \mathrm{cm}^{2}$, which was only one order of magnitude lower than the impedance of the intact coating. The developed coating provided enhanced long-term corrosion protection for AZ31 magnesium alloy both when the coating was intact and when it had artificial defect. The observed ability of the coated magnesium to withstand long-term immersion in concentrated $\mathrm{NaCl}$ solution and its insensitivity to local defect that we call fault-tolerance is explained by a combination of several factors, namely: high adhesion strength, high chemical, mechanical and hydrolytic stability and corrosion inhibiting effect provided by DETA.

\section{Acknowledgements}

This work was supported by Portuguese Foundation for Science and Technology (FCT) (projects PTDC/CTM-MET/112831/2009,
PTDC/CTM-NAN/113570/2009, PTDC/CTM-MET/113645/2009). The authors would like to acknowledge Airbus Group Innovations, Munich, for supplying the alloys. FP7 Marie Curie IRSES project SISET - Enhancing Scanning Ion-Selective Electrode Technique, FP7-PEOPLE-IRSES-GA-2010-269282 is acknowledged for the work related with the usage of simultaneous SVET-SIET.

\section{References}

[1] P.A. Sorensen, S. Kiil, K. Dam-Johansen., Anticorrosive coatings: a review, J. Coat. Technol. Res. 6 (2009) 135

[2] M.L. Zheludkevich, R. Serra, M.F. Montemor, I.M. Miranda Salvado, M.G.S. Ferreira, Corrosion protective properties of nanostructured sol-gel hybrid coatings to AA2024-T3, Surf. Coat. Technol. 200 (2006) 3084

[3] D. Wang, G.P. Bierwagen, Sol-gel coatings on metals for corrosion protection, Prog. Org. Coat. 64 (2009) 327.

[4] D. Raps, T. Hack, J. Wehr, M.L. Zheludkevich, A.C. Bastos, M.G.S. Ferreira, O. Nuyken, Electrochemical study of inhibitor-containing organic-inorganic hybrid coatings on AA2024, Corros. Sci. 51 (2009) 1012.

[5] A.N. Khramov, V.N. Balbyshev, L.S. Kasten, R.A. Mantz, Sol-gel coatings with phosphonate functionalities for surface modification of magnesium alloys, Thin Solid Films 514 (2006) 174.

[6] N.V. Murillo-Gutiérrez, F. Ansart, J.P. Bonino, S.R. Kunst, C.F. Malfatti, Architectural optimization of an epoxy-based hybrid sol-gel coating for the corrosion protection of a cast Elektron21 magnesium alloy, Appl. Surf. Sci. 309 (2014) 62.

[7] S.V. Lamaka, M.F. Montemor, A.F. Galio, M.L. Zheludkevich, C. Trindade, L.F. Dick, M.G.S. Ferreira, Novel hybrid sol-gel coatings for corrosion protection of AZ31B magnesium alloy, Electrochim. Acta 53 (2008) 4773.

[8] J. Hu, Q. Li, X. Zhong, L. Li, L. Zhang, Organic coatings silane-based for AZ91D magnesium alloy, Thin Solid Films 519 (2010) 1361.

[9] M.T. Rodríguez, J.J. Gracenea, S.J. García, J.J. Saura, J.J. Suay, Testing of the influence of the plasticizers addition on the anticorrosive properties of an epoxy primer by means of electrochemical techniques, Prog. Org. Coat. 50 (2004) 123.

[10] T.T.X Hang, T.A. Truc, T.H. Nam, V.K. Oanh, J.B. Jorcin, N. Pébère, Corrosion protection of carbon steel by an epoxy resin containing organically modified clay, Surf. Coat. Technol. 201 (2007) 7408

[11] L. Prezzi, L. Mascia, Network density control in epoxy-silica hybrids by selective silane functionalization of precursors, Adv. Polym. Technol. 24 (2005) 91.

[12] I. Díaz, B. Chico, D. de la Fuente, J. Simancas, J.M. Vega, M. Morcillo, Corrosion resistance of new epoxy-siloxane hybrid coatings. A laboratory study, Prog. Org. Coat. 69 (2010) 278

[13] L. Matejka, K. Dusek, J. Plestil, J. Kriz, F. Lednicky, Formation and structure o the epoxy-silica hybrids, Polymer 40 (1999) 171.

[14] T. Nazir, A. Afzal, H.M. Siddiqi, Z. Ahmad, M. Dumon, Thermally and mechanically superior hybrid epoxy-silica polymer films via sol-gel method, Prog. Org. Coat. 69 (2010) 100

[15] F. Brusciotti, D.V. Snihirova, H.B. Xue, M.F. Montemor, S.V. Lamaka, M.G.S. Ferreira, Hybrid epoxy-silane coatings for improved corrosion protection of $\mathrm{Mg}$ alloy, Corros. Sci. 67 (2013) 82.

[16] I.A. Kartsonakis, A.C. Balaskas, E.P. Koumoulos, C.A. Charitidis, G. Kordas, ORMOSIL-epoxy coatings with ceramic containers for corrosion protection of magnesium alloys ZK10, Prog. Org. Coat. 76 (2013) 459.

[17] R.-G. Hu, S. Zhang, J.-F. Bu, C.-J. Lin, G.-L. Song, Recent progress in corrosion protection of magnesium alloys by organic coatings, Prog. Org. Coat. 73 (2012) 129.

[18] D.K. Ivanou, M. Starykevich, A.D. Lisenkov, M.L. Zheludkevich, H.B. Xue, S.V Lamaka, M.G.S. Ferreira, Plasma amodized ZE41 magnesium alloy sealed with hybrid epoxy-silane coating, Corros. Sci. 73 (2013) 300

[19] S.V. Lamaka, R.M. Souto, M.G.S. Ferreira, In-situ visualization of local corrosion by Scanning Ion-selective Electrode Technique (SIET), in: A. Mendez-Vilas, J. Diaz (Eds.), Microscopy: Science, Technology, Applications and Education, Edition 2010, vol. 3, Formatex Research Center, Badajoz, Spain, 2010, pp. 2162-2173, Available on http://www.formatex.info/microscopy4/ 2162-2173.pdf (accessed 09.09.14).

[20] S.V. Lamaka, M. Taryba, M.F. Montemor, H.S. Isaacs, M.G.S. Ferreira, Quasisimultaneous measurements of ionic currents by vibrating probe and $\mathrm{pH}$ distribution by ion-selective microelectrode, Electrochem. Commun. 13 (2011) 20.

[21] D. Snihirova, S.V. Lamaka, M.G. Taryba, A.N. Salak, S. Kallip, M.L. Zheludkevich, M.G.S. Ferreira, M.F. Montemor, Hydroxyapatite microparticles as feedbackactive reservoirs of corrosion inhibitors, ACS Appl. Mater. Interfaces 2 (2010) 3011.

[22] A. Foyet, T.H. Wu, A. Kodentsov, L. van der Ven, G. de With, R. van Benthem, Impedance evaluation of permeability and corrosion of Al-2024 aluminum alloy coated with a chromate free primer, Prog. Org. Coat. 65 (2009) 257.

[23] N.N.A.H. Meis, L.G.J. van der Ven, R.A.T.M. van Benthem, G. de With, Extreme wet adhesion of a novel epoxy-amine coating on aluminum alloy 2024-T3, Prog. Org. Coat. 77 (2014) 176

[24] E. Barsoukov, J.R. Macdonald, Impedance Spectroscopy: Theory, Experiment, and Applications, 2nd edition, John Wiley \& Sons, Inc., Hoboken, New Jersey, 2005. 
[25] S.V. Lamaka, O.V. Karavai, A.A. Bastos, M.L. Zheludkevich, M.G.S. Ferreira, Monitoring local spatial distribution of $\mathrm{Mg}^{2+}, \mathrm{pH}$ and ionic currents, Electrochem. Commun. 10 (2008) 259.

[26] S.V. Lamaka, G. Knörnschild, D.V. Snihirova, M.G. Taryba, M.L. Zheludkevich, M.G.S. Ferreira, Complex anticorrosion coating for ZK30 magnesium alloy, Electrochim. Acta 55 (2009) 131.

[27] O.V. Karavai, A.C. Bastos, M.L. Zheludkevich, M.G. Taryba, S.V. Lamaka, M.G.S. Ferreira, Localized electrochemical study of corrosion inhibition in microdefects on coated AZ31 magnesium alloy, Electrochim. Acta 55 (2010) 5401.

[28] G. Williams, R. Grace, Chloride-induced filiform corrosion of organic-coated magnesium, Electrochim. Acta 56 (2011) 1894
[29] J.B. Bajat, I. Milošev, Ž. Jovanović, V.B. Mišković-Stanković, Studies on adhesion characteristics and corrosion behaviour of vinyltriethoxysilane/epoxy coating protective system on aluminium, Appl. Surf. Sci. 256 (2010) 3508.

[30] H. Shi, Z. Tian, T. Hu, F. Liu, E.-H. Han, M. Taryba, S.V. Lamaka, Simulating corrosion of $\mathrm{Al}_{2} \mathrm{CuMg}$ phase by measuring ionic currents, chloride concentration and pH, Corros. Sci. 88 (2014) 178.

[31] S.V. Lamaka, M.M. Lourenço, D.K. Ivanov, M.L. Zheludkevich, M.G.S. Ferreira, T Hack, Fault-tolerant composite protective coating for WE43 magnesium alloy, in: Proceedings of the IMA 2014 World Annual Magnesium Conference, 2014, p. 116. 